\title{
A pictogram-based intervention to reduce parental liquid medication errors: health literacy approach
}

\author{
Hanan Mohamed Mohamed Tork \\ Dept of Paediatric Health Nursing, Faculty of Nursing, Zagazig University, Egypt
}

Email address:

hotork@zu.edu.eg

\section{To cite this article:}

Hanan Mohamed Mohamed Tork. A Pictogram-Based Intervention to Reduce Parental Liquid Medication Errors: Health Literacy Approach. American Journal of Nursing Science. Vol. 2, No. 3, 2013, pp. 27-32. doi: 10.11648/j.ajns.20130203.12

\begin{abstract}
Evidence suggests that parents and caregivers make frequent errors when administering liquid medications to children. These errors, which include inaccurate dosing as well as non-adherence to medication regimens, place children at risk for morbidity and mortality. The study aim to explore the effectiveness of pictogram based intervention in reducing caregivers' liquid medication errors as well as the extent to which health literacy impacts medication errors. Quasi-experimental study of caregivers $(n=250)$ of young children $(<6$ years) enrolled at primary pediatric clinic in Zagazig University hospital. A total of 250 caregivers (121 standard medication counseling and 129 pictogram based intervention) were assessed for health literacy by means of the Newest Vital Sign measure; $84.4 \% \%$ had low health literacy (Newest Vital Sign score 0-3). Pictogram based intervention recipients were less likely to make errors in knowledge related to medication storage (26.6\% vs. $63.3 \%)$ dose frequency $(20.2 \%$ vs. $25 \%)$, and preparation compared with caregivers of standard medication counseling recipients (12.8\% vs. 31.7\%). Pictogram was an efficient way to reduce the prevalence of caregivers' liquid medication errors.
\end{abstract}

Keywords: Pictogram, Intervention, Medication Errors, Pediatric Caregiver, Parents, Health Literacy

\section{Introduction}

Worldwide, a large number of children are prescribed drugs on an outpatient basis and medication errors are fairly common in these settings [1]. Recent findings indicate that most preventable adverse drug events in pediatric outpatients are attributable to errors in medication administration [2]. Errors occur frequently; $50 \%$ of parents or more make errors when dosing liquid medications [3]. Though this matter has been well recognized as a cause of concern, limited data is available from ambulatory settings [1]. The prevalence of medicine use in children, both prescribed and over-the-counter (OTC) is reported to be high [4].

Medication errors can be defined as errors that may occur at any step, starting from ordering a medication, to dispensing, administration of the drug and the subsequent monitoring. The outcomes of such errors are variable and may range between those that are clinically insignificant to a life threatening event [1]. The stages of the medication process include ordering/prescribing, transcribing/verifying, dispensing/delivering, and administering; medication errors with pediatric patients have occurred at every stage of the process [5]. For many reasons, pediatric patients are at par- ticular risk for administration errors, administration of oral liquids and tablet splitting are often inevitable to individualize doses [6], which are all error-prone [7]. In addition, in pediatric patients, errors are three times more likely than in adults, with younger and critically ill children being particularly susceptible to adverse outcomes [8]. Dosing errors by parents were highly prevalent with cups compared with droppers, spoons, or syringes. Strategies to reduce errors should address both accurate use of dosing instruments and health literacy [9]. Thus, interventions are needed to decrease medication errors and improve patient safety through safe medication practices. In particular, preventing medication errors is an important part of ensuring safe and quality patient care in the pediatric population.

Medication errors frequently cause preventable Adverse Drug Events (ADEs) if they occur during drug prescription or administration [10]. However, preventive strategies should also address drug administration because one-third of the medication errors leading to ADEs occur at that stage [11]. In contrast, strategies preventing administration errors are rare, although those errors are frequent [12]. Dealing with the problem of medication errors in outpatients would require a different approach. Inclusion of pictographic in- 
formation, such as pictograms or simple diagrams, as part of medication instructions is a potential strategy for decreasing dosing errors [13]. Pictograms are descriptive symbols that illustrate information, medicine-related pictograms can be used to clarify drug information especially for elderly persons [14], persons with low literacy skills and also for children [15]. Pictograms have been developed and widely used in USA, Europe and Africa, $(15,16]$. The United States Pharmacopeia (USP) has developed and published 81 medicine-related pictograms [17]. Pictogram-based intervention used as part of medication counseling resulted in decreased medication dosing errors and improved adherence among multiethnic, low socioeconomic status caregivers whose children were treated at an urban pediatric emergency department [18].

\section{Health Literacy}

Health literacy has been defined as the ability to obtain, process, and understand basic health information and services needed to make appropriate health decisions [19]. It is distinguished from literacy in its focus on health-related issues and its inclusion of a "functional" component related to ability to act on and apply health information, including the ability to access and navigate the health care system [20]. According to Lee et al., [21], low health literacy is considered a worldwide health threat. Low health literacy has been associated with difficulty interpreting medication labels as well as dosing errors [9, 22]. Those from low socioeconomic status (SES) backgrounds are more likely to have low health literacy and are at particular risk for errors [23]. An additional factor that may play a role, particularly in low income, is Limited English Proficiency (LEP). LEP is a well-recognized risk factor for adverse health outcomes [24]. One mechanism through which LEP acts is through the ability to comprehend written materials, a skill that overlaps with health literacy, particularly where medication labels are typically in English [25]. The role of literacy in health care has been less extensively studied for child health compared with adult health [26].

Research to date has focused mostly on reading ability as a proxy measure for health literacy [27]. Some measures of reading ability use health care words or paragraphs that contain health-related content to assess research participants, but such instruments (such as the Rapid Estimate of Adult Literacy in Medicine [REALM] and Test of Functional Health Literacy in Adults [TOFHLA]) are highly correlated with generic reading tests and still focus on the skill of reading or interpreting information rather than a broader set of functional skills [28].

\subsection{Significance of the Study}

Among children, the rate of potentially dangerous medication errors is three times that of adults and outpatient wrong dose ordering errors are common [29,30]. Although the majority of pediatric medications are taken at home, data on parental medication errors are limited, and risks for children with chronic conditions, who use many medicines, may be great [31]. Certain strategies have been advocated to reduce the frequency of medication errors. Knowledge based errors can obviously be prevented by promoting the health literacy of caregivers [1].

\section{Study Methodology}

\subsection{Study Design}

Quasi-experimental design was used to explore whether parents given a pictogram based intervention would make fewer dosing errors compared to parents given standard medication counseling.

\subsection{Participants and Setting}

A convenience sample was enrolled of caregivers presenting with their children to the pediatric outpatient clinic at Zagazig University Hospital, in Zagazig city. The caregivers were approached while waiting in the clinic. The pediatric outpatient clinic primarily serves families of low socioeconomic status. The study was verbally described and simple toys were provided to children as study incentive to encourage caregivers' participation. Inclusion criteria were parent/legal guardian having a child aged 30 days through 6 years, who is responsible for administering prescribed liquid medication to their children. Enrolled caregivers were randomized to receive the pictogram-based Intervention or standard medication counseling (control group). Data collection took place from June through August 2011.

\subsection{Assessments}

Assessments were performed at baseline before intervention and it consisted of three parts, first; socio-demographic characteristics, including the child's age and sex as well as caregiver age, marital status, relationship to the child, residence and educational level were obtained via a structured questionnaire. Second; the child's medical history including history of chronic illness and whether the child took medication in a regular manner. Third; caregiver health literacy level which assessed using the Newest Vital Sign (NVS) measure. Scores on the NVS range from 0-6, with a score of 0-1 indicating a "high likelihood of limited literacy," 2-3 a "possibility of limited literacy," and 4-6 adequate literacy. The NVS assesses literacy skill on the basis of parent ability to answer questions about a nutrition label from an ice cream container, with 4 of the 6 total questions focused on the evaluation of quantitative literacy skills. Caregivers who were categorized as having a "high likelihood of limited literacy" or "possibility of limited literacy" were combined into one "low health literacy" category, and compared to those with adequate literacy as previous studies did [32]. 

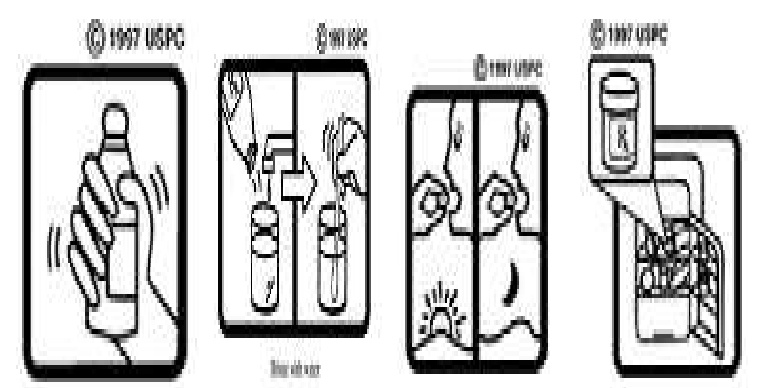

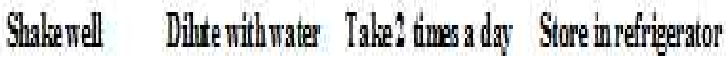

Figure 1. Examples of USP pictograms (USP; The United States Pharmacopeial Convention, 1997)

\subsection{Intervention}

The interventions were conducted by the researcher and two research assistants who were trained by the author. The interventions were done in the waiting hall of the pediatric outpatient clinic in Zagazig University hospital. A total of two hundred and fifty caregivers were participated; 121 of them were allocated randomly to receive standard medication counseling (control group) and the rest (129) of participants were received pictogram based intervention (intervention group). A total of 10 pharmaceutical pictograms with text were used and the size of the pictograms shown was $80 \mathrm{~mm} \times 80 \mathrm{~mm}$. The selection criterion of the pictograms for this study was that the pictogram should be suitable for drug information directed for adult. The drug information used was taken from the medicine leaflets e.g. indication, preparation, side effects, storage and dosing was based on the physician prescription. An average of six caregivers were interviewed per day for both intervention and control groups. Each caregiver took an average of 45-60 minutes for assessment and intervention. Approval for the study was obtained from the Ethical Committee of the Faculty of Nursing, Zagazig University as well as the administration of the University hospital. In addition, informed consent was obtained from all participants after brief description for the study aim and the nature of intervention.

\section{Data Analysis}

Data were analyzed using SPSS version 16.0 statistical software (SPSS Inc, Chicago, Illinois). A 2-tailed P value of $<.05$ was considered to be statistically significant. The researcher estimated the rate of low health literacy of $50 \%$ on the basis of prior studies [13].

Table 1. Descriptive Data of the participants

\begin{tabular}{|c|c|c|}
\hline Characteristics & $\begin{array}{l}\text { Pictogram based } \\
\text { intervention } \\
(n=129)\end{array}$ & $\begin{array}{c}\text { Standard Medication Coun- } \\
\text { seling } \\
(\mathrm{n}=121)\end{array}$ \\
\hline Children & & \\
\hline Children in household, mean (SD) & $3.0(1.7)$ & $3.0(1.2)$ \\
\hline Age mean $(\mathrm{SD})$ & $2.6(2.1)$ & $2.2(2.7)$ \\
\hline Male & 44.5 & 39.7 \\
\hline Caregivers & & \\
\hline Age, mean (SD) & $31.2(6.5)$ & $33.1(7.3)$ \\
\hline${ }^{\mathrm{a}}$ Education & & \\
\hline Read and write & $87(67.4)$ & $73(60.3)$ \\
\hline Secondary & $9(7.0)$ & $37(30.5)$ \\
\hline Higher (college or greater) & $32(24.8)$ & $11(9.2)$ \\
\hline Relationship to child & & \\
\hline Mother & $108(83.7)$ & $96(79.3)$ \\
\hline Father & $11(8.5)$ & $19(15.7)$ \\
\hline Others & $10(7.8)$ & $6(5)$ \\
\hline Marital status & & \\
\hline Married & $110(85.3)$ & $99(81.8)$ \\
\hline Separated/divorced/widowed & $19(14.7)$ & $22(18.2)$ \\
\hline Residence & & \\
\hline Urban & $30(23.3)$ & $19(15.7)$ \\
\hline Rural & $99(76.7)$ & $102(84.3)$ \\
\hline *Health literacy (NVS) & & \\
\hline Low health literacy & $112(80.8)$ & $99(81.8)$ \\
\hline Adequate literacy & $17(13.2)$ & $21(17.4)$ \\
\hline
\end{tabular}

*Health literacy measured using Newest Vital Sign (NVS)

${ }^{\mathrm{a}}$ Missing data for one subject. 


\section{Results}

A total of two hundred and fifty caregivers who attended the pediatric outpatient clinic in Zagazig University hospital and met inclusion criteria were participated in the study. The majority of study subjects were mothers $(81.6 \%)$, their age ranged from 17 to 61 years, with a mean age of 32.2 years. Of 250 caregivers enrolled in the study, 129 (51.6\%) were allocated randomly to receive pictogram based intervention, whereas 121 (48.4\%) were allocated to the receive standard medication counseling (control group). For the total sample, 211 caregivers $(84.4 \%)$ had low health literacy $(54.1 \%$ high likelihood of limited literacy, $30.3 \%$ possible limited literacy) table 1.

Figure 1 represents a sample of the pictogram that used during intervention phase which adopted from the United States Pharmacopeia Inc. As shown in figure 2, pictogram based intervention recipients were less likely to make errors in knowledge related to medication storage $(26.6 \%$ vs. $63.3 \%)$ dose frequency $(20.2 \%$ vs. $25 \%)$, and preparation compared with caregivers of standard medication counseling recipients $(12.8 \%$ vs. $31.7 \%)$. while there was no statistically significant differences in knowledge related to medication's name and indications between both groups.

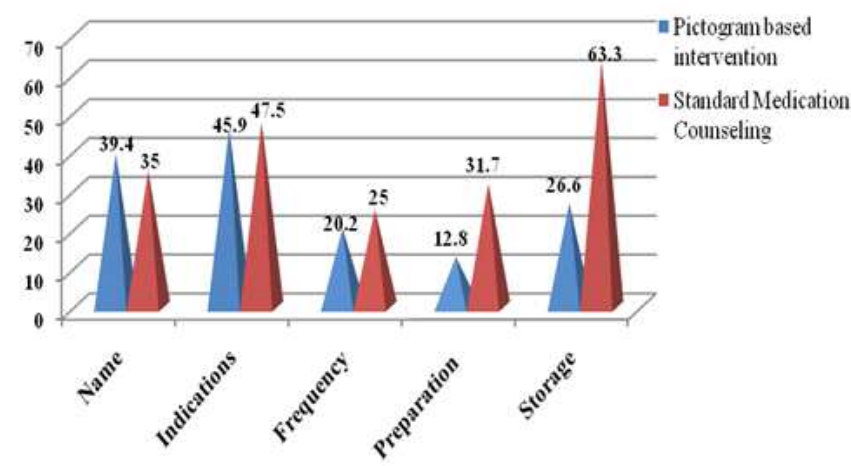

Figure 2. Medication Knowledge and Related Practices

As shown in table 2, association between caregivers health literacy and medication errors category revealed that caregivers with adequate health literacy in pictogram based intervention group were less likely to make small ( $>20 \%$ to $40 \%$ above/below recommended dose) and large ( $>40 \%$ of recommended dose) dosing errors compared to caregivers with low health literacy $(35.3 \%$ vs. $74 \%)$, and this difference was statistically significant. The caregivers with low health literacy in pictogram based intervention group significantly less likely to make dosing errors compared to those who had low health literacy in control group (74\% vs. 97\%) (Table 2).

Givers with adequate health literacy in pictogram based intervention group as well as in control group (standard medication counseling group) were less likely to make a dosing error ( $>20 \%$ deviation) compared to caregivers with low literacy (35.3\% vs. $57.1 \%$ ) and (50\% vs. $69.7 \%)$ respectively, this difference was statistically significant. With those caregivers in the pictogram based intervention group significantly less likely to make a dosing error $(>20 \%$ deviation) compared to those who received counseling-only (57.1\% vs. $69.7 \%$ ). Caregivers of the pictogram based intervention group were also significantly less likely to make large errors in overdosing $(>1.5$ times the recommended dose) $(14.7 \%$ vs. $23.1 \%)$ (Table 2$)$.

\section{Discussion}

Several prior studies have demonstrated that parents have difficulty measuring liquid medications. [7, 9, 18]. Pictograms have previously been found to help improve parent medication knowledge and adherence $(33,34)$. The present study aimed to explore the effectiveness of the pictogram based intervention in reducing the caregivers' liquid medication errors. The results revealed statistically insignificant difference between the intervention and control groups as regards to their age $(31.2 \pm 6.5,33.1 \pm 7.3)$. In addition, the majority of caregivers for both groups (intervention and control) were mothers and regarding to their education; the most of the pictogram based intervention and standard medication counseling groups were read and write which support the homogeneity of the sample.

The present results revealed that a pictogram-based intervention significantly improved caregivers' knowledge as regards to medication' frequency, preparation and storage. These findings is consistent with the randomized controlled trial conducted by Yin et al., in an urban public hospital pediatric emergency department, the efficacy of pictogram-based health literacy intervention to decrease administration errors by caregivers of young children when using liquid medications was evaluated. With this intervention it was found that caregivers had fewer errors in observed dosing accuracy ( $>20 \%$ deviation from prescribed dose) compared with caregivers who received routine counseling [18]. Hence standardized prescription with pictogram can be used and particularly useful in areas with low literacy levels. There is growing recognition that health literacy is a dual function, involving not only an individual's literacy skills when a task is approached but also how navigable and clearly the task is presented [35]. A disproportionate burden of outpatient medication errors is shouldered by families with low health literacy [9].

Similar to findings of the previous health literacy studies $[36,37]$, which documented that poorer educational attainment was found to be associated with lower levels of health literacy, furthermore, adults living in rural areas tended to have a lower level of health literacy than adults living in urban areas, the present study found most of participated caregivers $(84.4 \%)$ were considered to have low health literacy which may be due to that the most of them (80.4\%) were living in rural areas and their modest level of educa- 
tion ( $64 \%$ only able to read and write). The present findings demonstrated that the caregivers who had adequate health literacy were less likely to make dosing errors than those of low health literacy. These results indicated that health literacy particularly important for dosing accuracy, this suggests that improving caregivers' health literacy is one strategy to decrease dosing errors. Hence, the use of developed and efficient learning tools for caregivers e.g. using the pictograms, dosage forms, educational leaflet, in addition to audio and visual recording of appropriate medication use is recommended. This study presents initial data that can be used to design future studies with parents/caregivers. In addition, this study documents the extent of existing problem with caregivers' errors in pediatric liquid medications, and may serve as a baseline to assess future improvements. The present study has several limitations; caregivers' health literacy was assessed in Arabic and this may not reflect their true ability to perform health-related tasks in real life or if the assessment were administered in English; the language of the most medication leaflets. Due to the health literacy approach of the study, the participants were limited to those who literate and higher regarding their educational level in spite of nearly $27 \%$ of Egyptian are illiterate in addition, the femaleilliteracy rate is even worse; $20 \%$ higher than among males, particularly in the 15 to 35 age group [38].

Table 2. Dosing Error rate by Intervention type given and health literacy level

\begin{tabular}{|c|c|c|}
\hline Medication errors category & $\begin{array}{l}\text { Pictogram based } \\
\text { intervention }\end{array}$ & $\begin{array}{c}\text { Standard Medication } \\
\text { Counseling }\end{array}$ \\
\hline $\begin{array}{l}\text { Entire group } \\
\text { No errors }(\leq 20 \% \text { of } \\
\text { recommended dose })\end{array}$ & $\begin{array}{l}(\mathrm{n}=129) \\
40(31) \\
\text { Low Health Literacy }\end{array}$ & $(\mathrm{n}=121)$ \\
\hline $\begin{array}{l}\text { Any errors ( }>20 \% \text { to } 40 \% \text { above/below } \\
\text { recommended dose) } \\
\text { Large errors }(>40 \% \text { of recommended } \\
\text { dose) }\end{array}$ & $\begin{array}{l}\mathrm{n}=112 \\
64(57.1) \\
19(16.9)\end{array}$ & $\begin{array}{l}\mathrm{n}=99 \\
69(69.7) \\
27(27.3)\end{array}$ \\
\hline $\begin{array}{l}\text { Any errors ( }>20 \% \text { to } 40 \% \text { above/below rec- } \\
\text { ommended dose) }\end{array}$ & $\begin{array}{l}\text { Adequate Health Literacy } \\
\mathrm{n}=17 \\
6(35.3)\end{array}$ & $\begin{array}{l}n=22 \\
11(50)\end{array}$ \\
\hline Large errors ( $>40 \%$ of recommended dose) & $0(0.0)$ & $1(4.5)$ \\
\hline
\end{tabular}

+ The example for this table. The example for this table. The example for this table. The example for this table. The example for this table. The example for this table.

\section{Acknowledgements}

The author likes to thank all of the caregivers who willingly contributed to this research as well as the administration of Zagazig University hospital and pediatricians. Also I'd like to thank the research assistants who cooperated in conducting the study.

\section{References}

[1] Mehndiratta S (2012): Strategies to reduce medication errors in pediatric ambulatory settings. Journal of Postgraduate Medicine. 58:47-53.

[2] Zandieh SO, Goldmann DA, Keohane CA, Yoon C, Bates DW, Kaushal R. (2008): Risk factors in preventable adverse drug events in pediatric outpatients. J Pediatr. 152(2):225-231.

[3] Frush KS, Luo X, Hutchinson P, Higgins JN. (2004): Evaluation of a method to reduce over-the-counter medication dosing error. Arch Pediatr Adolesc Med. 158(7):620-624.

[4] Hämeen-Anttila K., Honkanen L., and Vainio K. (2009): The usability of medicine education assignments for seven to nine year-old children. Health Educ. 109, 491-506.
[5] Antonow, J., Smith, A., \& Silver, M. (2000): Medication error reporting: A survey of nursing staff. Journal of Nursing Care Quality. 15, 42-48.

[6] Quinzler R, Gasse C, Schneider A, et al. (2006): The frequency of inappropriate tablet splitting in primary care. Eur J Clin Pharmacol. 62:1065-73.

[7] Sobhani P, Christopherson J, Ambrose PJ, et al. (2008): Accuracy of oral liquid measuring devices: comparison of dosing cup and oral dosing syringe. Ann Pharmacother. 42:46-52.

[8] Kaushal R, Bates DW, Landrigan C, et al. (2001): Medication errors and adverse drug events in pediatric inpatients. JAMA. 285:2114-20.

[9] Yin HS, Alan L, Mendelsohn AL, Wolf MS, Parker RM, Fierman A, Schaick LV.; Bazan IS.; Kline; Dreyer BP. (2010): Parents' Medication Administration Errors: Role of Dosing Instruments and Health Literacy. Arch Pediatr Adolesc Med. 2010; 164(2):181-186.

[10] Bertsche T, Bertsche A., Krieg,N Kunz, K Bergmann, Hanke G. Hoppe-Tichy T. Ebinger F. WE Haefeli WE. (2010): Prospective pilot intervention study to prevent medication errors in drugs administered to children by mouth or gastric tube: a programme for nurses, physicians and parents. Qual Saf Health Care. 19-26. 
[11] Krähenbühl-Melcher A, Schlienger R, Lampert M, et al. (2007): Drug-related problems in hospitals: a review of the recent literature. Drug Saf. 30:379-407.

[12] Alexander DC, Bundy DG, Shore AD, et al. (2009): Cardiovascular medication errors in children. Pediatrics. 124:324-32.

[13] Yin HS, Mendelsohn AL, Fierman A, et al. (2011): Use of a pictographic diagram to decrease parent dosing errors with infant acetaminophen: a health literacy perspective. Acad Pediatr.11:50-57.

[14] [14] Patanwala IM, Brocklebank V, Inglis J. Trewby PN. A randomized questionnaire based study on the impact of providing numerical information on colorectal cancer screening. J R Soc Med Sh Rep 2011; 2:48.

[15] Hämeen-Anttila K, Kemppainen K, Enlund H, Patricia JB, Marja A. Do pictograms improve children's understanding of medicine leaflet information? Patient Education and Counseling 55 (2004) 371-378.

[16] [16] Mansoor LE, Dowse R. Effect of pictograms on readability of patient information materials. Ann Pharmacother 2003;37: 1003-9.

[17] United States Pharmacopeial Convention Inc. USP Pictograms. Retrieved 21 March 2012 from http://www.usp.org/].

[18] Yin HS., Dreyer BP., Schaick L., Foltin GL., Dinglas C., Mendelsohn AL.(2008): Randomized Controlled Trial of a Pictogram-Based Intervention to Reduce Liquid Medication Dosing Errors and Improve Adherence Among Caregivers of Young Children. Arch Pediatr Adolesc Med. 162(9):814-822.

[19] Berkman N, DeWalt D, Pignone M, et al. (2004): Literacy and health outcomes. Summary, evidence report/technology assessment no. 87. Rockville, MD: Agency for Healthcare Research and Quality.

[20] Schwartzberg JG, Van Geest JB, Wang CC, eds. (2005): Understanding Health Literacy: Implications for Medicine and Public Health. Chicago, Ill: AMA Press.

[21] Lee SD, Tsai T, Tsai Y and Kuo KN. (2010): Health literacy, health status, and healthcare utilization of Taiwanese adults: results from a national survey. BMC Public Health. 10:614.

[22] King JP, Davis TC, Bailey SC, et al. (2011): Developing Consumer-Centered, Nonprescription Drug Labeling: A Study in Acetaminophen. American Journal of Preventive Medicine. 40(6):593-598.

[23] Rothman RL, Yin HS, Mulvaney S, Co JP, Homer C, Lannon C. (2009): Health literacy and quality: focus on chronic illness care and patient safety. Pediatrics.124 (3):S315-326.

[24] Bailey S, Agarwal N, Sleath B, Gumusoglu S. (2011): Im- proving Drug Labeling and Counseling for Limited English Proficient Adults. Journal of Health Care for the Poor and Underserved. 22(4):1131-1143.

[25] Weiss L, Gany F, Rosenfeld P, et al. (2007): Access to Multilingual Medication Instructions at New York City Pharmacies. Journal of Urban Health. 84(6):742-754.

[26] DeWalt DA and Hink A (2009): Health Literacy and Child Health Outcomes: A Systematic Review of the Literature. Pediatrics. 124; S265.

[27] DeWalt DA, and Pignone MP. (2005): Reading is fundamental: the relationship between literacy and health. Arch Intern Med. 165(17): 1943-1944.

[28] DeWalt DA, Berkman ND, Sheridan SL, Lohr KN, Pignone M. (2004): Literacy and health outcomes: a systematic review of the literature. J Gen Intern Med. 19(12):1228-1239.

[29] American Academy of Pediatrics (2003): Prevention of medication errors in the inpatient setting. Pediatrics. 112: 431-436.

[30] McPhillips HA, Stille CJ, Smith D, et al. (2005): Potential medication dosing errors in outpatient pediatrics. J Pediatr. 147: 761-767.

[31] Slonim DA, LaFleur BJ, Ahmed W, et al. (2003): Hospital-reported medical errors in children. Pediatrics. 111: 617-621.

[32] Weiss BD, Mays MZ, Martz W, et al. (2005): Quick assessment of literacy in primary care: the newest vital sign. Annals of Family Medicine. 3(6):514-522.

[33] Katz MG, Kripalani S, Weiss BD. Use of pictorial aids in medication instructions: a review of the literature. Am J Health-System Pharmacy. 2006;63:2391-2396.

[34] Dowse R, Ehlers M. Medicine labels incorporating pictograms: do they influence understanding and adherence? Patient Educ Couns. 2005;58:63-70.

[35] Nielsen-Bohlman LT, Panzer AM, Kindig DA, eds. Health literacy: A prescription to end confusion. 1st ed. Washington, DC: National Academies Press; 2004.

[36] Wagner C, Knight K, Steptoe A, Wardle J: Functional health literacy and health-promoting behaviour in a national sample of British adults. J Epidemiol Community Health 2007, 61(12): 1086-1090.

[37] Kutner M, Greenberg E, Yin J, Paulsen C, White S: The health literacy of America's adults: Results from the 2003 national assessment of adult literacy. US Department of Education. Washington, DC 2006.

[38] UNICEF (2010): Information by country and programme. Retrieved $15 \quad$ May 2012 from [http://www.unicef.org/infobycountry/egypt_statistics]. 